\title{
Formation of a Cluster-Managing Model for an Innovative Development in a Region of the Russian Federation
}

\author{
Anna E. Strelyaeva \\ Tatiana I. Shirko \\ National Research Tomsk Polytechnic University, Russian Federation \\ Email: strelk-s@mail.ru
}

\section{Doi:10.5901/mjss.2015.v6n3s5p99}

\begin{abstract}
At the modern development stage of post-industrial society in the world economy the processes of globalization and specialization of national markets significantly enhance the competition among countries, among regions and among individual producers inside a country. Against this background the governmental authorities of the Russian Federation, while preserving the country's global leadership in the energy sector, recognize the competitive economy and high-tech solutions as the longterm development strategy of the country. Following this line of policy, in the period between 2012 and 2014, Russian regions implemented cluster policy based on the federal and regional innovative development strategies. Among pilot cluster projects financed by the federal budget is the territorial cluster "Pharmaceutics, Medical Equipment and Information Technologies" formed in Tomsk Region that has unique starting opportunities for the formation of a stable innovative regional system, i.e., it has a developed scientific and educational complex as well as small and medium-size innovation enterprises with their state-ofthe-art technological solutions in pharmaceutics and medical equipment. The two years of the Cluster's activity, with financial support from governmental authorities, were acknowledged as successful. In the long term plans it is intended to expand both the range of pharmaceutical products and cooperation with other Tomsk clusters.
\end{abstract}

Keywords: regional development, strategic planning, regional clusters, interfirm relationships, new product development, small and medium enterprises

\section{Introduction}

By 2003 a final stage of transition to the market economic system was reached in the Russian Federation, a stable economic growth was achieved, a foundation for large-scale structural and institutional changes was created. Consequently, starting from mid-2000s, Russia set long-term development goals that could provide a high level of welfare for the population and promote the geopolitical position of the country as that of a global political and economic leader. Problems of improving the efficiency of economic institutions that promote public welfare and living standards of the population by developing long-term national strategy of social and economic development became challenging in the country (Freeman 1995). The basic trend of Russia's long-term development, in line with global economic development tendencies, is the country's innovation strategy based on the concentration of efforts by the society, state, business and science in order to develop fundamentally new competitive technologies and products in the economic sphere of public life (Inglehart, 1995).

Furthermore, due to the federal nature of Russia, the formation and development of Russia's innovation potential envisages a development of own innovation media in separate subjects of the Russian Federation taking into account the regional development specifics, available resources, personnel and infrastructure (Raagmaa, 2002). One of the essential instruments of regional development is the implementation of cluster policy in federal subjects and formation of local clusters that combine enterprises, suppliers of equipment, of components, specialized production and maintenance services, scientific research and educational institutions and are bound by the relations of territorial vicinity and functional dependence in the sphere of production and sales of goods and services (Kuznetsov et al., 2014).

In this regard the macro-region of Western Siberia is of special interest, its potential resources being substantial enough for the formation of successful clusters that may turn into "growth points" of Russian economy (Enright, 2000). It is therefore regarded necessary to have a complex study of the innovation territorial clusters formed within Western Siberia as the instruments for developing competitiveness and innovations as well as to analyze the formation of regional innovational structure and the interaction of stakeholders of the regional innovation system. The experience of formation 
of the innovation territorial cluster "Pharmaceutics, Medical Equipment and Information Technologies" in Tomsk Region, a subject of the Russian Federation that possesses unique starting possibilities for the formation of a stable innovation regional system, serves as the investigation model in the present work.

\section{Research Methodology}

One of the central theories employed in the investigation was the theory of modernization, a leading theoretical development that explains the unevenness of development of separate societies and civilizations. According to the theory of modernization the global historic progress is based on a multi-variant process of transforming all the traditional societies into modern societies under the impact of a complex of factors. One of the key modernization parameters is the qualitative change of economic and political institutes (Sztompka, 2004). Russia belongs to the "second tier" of modernization that is characterized by the leading part the state power in the historical development process as well as by the collision of traditional and of borrowed systems of values (Tiryakian, 2007). This problem investigation also used a system approach to the study of methods of formation and functioning of innovation clusters as of a key factor for improving the competitiveness of high-tech branches and of Russian economy in general. The system approach, using abstract means, makes it possible to attack the modeling of complicated, multi-dimensional processes by notably simplifying the solution of a specific problem without losing, at the same time, the entire range of properties of the analyzed phenomena. Another advantage of the system approach is the possibility to treat a territorial cluster as a system which is based on the method of arranging the actions that cover a certain sort of activities by highlighting the regularities and interrelations.

\section{Managing the Innovative Development of a Region in the Russian Federation}

The transition of the Russian Federation to an innovative type of development takes place in presence of an infrastructure specific to Russia (Simmie, 1999). In a number of its innovative development indicators Russia is substantially behind the developed countries; it had no track record in developing methodological principles of the national innovation system; the problem of forming innovation sphere institutes still exists. Hence, when the Russian Federation Government was developing basic strategic documents determining the strategy of economic development of Russia, it was decided to provide priority development opportunities to the sectors of Russian economy that determine its specialization in the global economy management system and make it possible to maximally attain the national competitive advantages. The main priorities in the national development are preserving Russia's global leadership in the energy sector and forming a competitive economy of knowledge and high-tech solutions.

\subsection{Regions of Russia as innovation policy objects and subjects}

In the 1990s, the federal economic policy regarding the regions of Russia was formulated by leveling off their social and economic development rate. The need for this sort of policy was caused by a number of interconnected factors. Modern regional organization of the Russian Federation was formed during the planned industrialization epoch of the Soviet period when the regions were treated as an aggregate of geographically connected industrial and technological areas that provide balance and growth of the economy (Bergman, 1999). This way of arranging the regional economic space in the period of forming market economy institutes ceased to satisfy the scale of economic and social processes of the open market.

Therefore, starting from mid-2000s, the Government of Russia reconsidered the basic approach to realizing the social and economic policy and formulated the problem of implementing a general structural economic reform in the country based on ensuring Russia's scientific and technological leadership in the fields that provide the country's competitive advantages (Tkachenko \& Bogachev, 2014). Among the basic instruments of regional policy is the elaboration of innovation development concepts and strategies for the subjects of the Federation and formation of special economic zones, high-tech industrial parks, technology cities in Russian regions and construction of Innovation Center "Skolkovo", the first in Russia; all of these being scientific and technological complexes for the development and commercialization of new technologies.

To implement the goal, Decree No 2227-p dated 8th December 2011 "About Approving the Strategy of Innovation Development of the Russian Federation for the Period Through to 2020" by the Government of Russia approved the basic innovation policy trends for Russian regions. The immediate problem for the regions was to improve the institutional medium and the mechanisms of usage of the regional innovation infrastructure by developing regional programs and 
strategies of innovation development with the involvement of scientific and educational institutions concerned, of enterprises, of small and medium-size businesses (Tkachenko \& Bogachev, 2014). It envisaged a formation of developed innovation infrastructure in the regions, the provision of a continuous innovation cycle starting with the investigation and through to commercialization for the established and growing companies, promotion of the innovation products entering the regional, Russian and international markets. Involvement of all the subjects of the Russian Federation in the formation of basic infrastructure taking into account the development degree of their scientific and educational complex and innovational entrepreneurship was of principal importance for the strategy.

\subsection{Cluster policy as the instrument of innovative regional development of the Russian Federation}

One of the priority trends of formulating the innovation strategy by the Government of Russia, aimed at the competitiveness improvement, was the implementation of cluster policy in the regions. The main target of cluster policy is to promote growth of business competitiveness through effective interaction of cluster participants due to their geographical closeness, improved access to innovations, technologies, know-how, specialized services and highly qualified personnel, reduction of transaction costs, and realization of joint cooperation projects (Andersson, 2004). Clusters formation and development is an effective mechanism of attracting direct foreign investments and integration of Russian clusters into the world market of high-tech products. The activity of an innovation territorial cluster results in innovative goods and services (Clark, 1998).

In order to promote the innovation development of regions the subjects of the Russian Federation will be afforded with subsidies on a competitive basis for use in the cluster development. After competitive selection and according to the priority trends of scientific and technical policy, in August 2012 the Government of the Russian Federation prepared a list of pilot innovation territorial clusters who were granted state financial support. The list contained 25 innovation territorial clusters and the cluster "Pharmaceutics, Medical Equipment and Information Technologies" formed in Tomsk Region was also included in the list.

\subsection{Tomsk region is a regional venue for implementing the cluster policy}

Tomsk Region is a subject of the Russian Federation located within Western Siberia that has a significant competitive advantage for the development of an innovative model of economy. Tomsk Region is a dynamically developing region of Russia where the average per capita income amounts to 33.2 thousand rubles (as of 2012). The region traditionally holds itself as one of the major oil- and -gas areas and as one of the leading scientific and educational centers of Russia. There are 10 establishments functioning in Tomsk Region that carry out programs of higher professional education; they include 6 state universities (with 2 of the universities being national research institutes), 6 institutes of the Russian Academy of Sciences and 6 institutes of the Russian Medical Academy of Sciences. Starting from 2007 the share of scientific and educational complex in the gross regional product of Tomsk Region persistently exceeded 5\% (Tomskstat, 2015).

The share of population with higher education in the aggregate number of persons involved in the economy of Tomsk Region in 2010 amounted to $32 \%$. Tomsk Region, in terms of this indicator, is placed the $12^{\text {th }}$ among the regions of the Russian Federation, while it is ranked the first in terms of the concentration index of scientific employees of top qualification, i.e., of doctors and masters of sciences. Patent activity of Tomsk Region is twice higher than the mean activity within the Russian Federation. For instance, in 2010, the patent activity in Tomsk Region amounted to 5.52\% while the average index within the Russian Federation amounted to 2.85\%.

Late 90s witnessed the formation and functioning of small-sized enterprises established by the graduates of Tomsk higher educational institutions who pursued science and who launched small-sized enterprises producing high-tech products. This is why practically all the small- and medium-sized enterprises producing medical machinery and apparatus emerged based on the results of scientific research and development in the universities and scientific research institutions of Tomsk Region. But at the same time, there was a substantial defect in the innovative infrastructure of the region: i.e., absence of a modern engineering center equipped with respective manufacturing machinery, pilot production units for use in the implementation of research and analytical R\&Ds.

Between late 1990s and early 2000s the Region was implementing its stabilization program of social and economic development through the development of an export-oriented branch, i.e., oil and gas industry, whose tax revenues to the regional budget constituted more than one third of the receipts. In 2001 to 2005, the Region implemented the financial stabilization program and the planned level of gross regional product was attained. But at the same time, the industrial production rate and investment generation were inadequate. So, after having approved it with the federal authorities, in 2005 the regional administration developed and adopted the Strategy of Social and Economic Development of Tomsk 
Region up to 2020 whose core principle was the innovation approach. The development of the Strategy basing on longterm strategic priorities was one of the first Russian cases of using modern approaches to strategic management.

The Strategy was targeted at the structural adjustments of the regional model of economy, provision of sustainable social and economic development of Tomsk Region as of a subject of the Russian Federation and at the use of its scientific and educational potential. A most important implementation tool for the Strategy and for the programs of social and economic development elaborated within the program's framework was the regional cluster policy announced which was geared to the provision of support to developing groups of enterprises, scientific and educational institutions of the region which are consolidated with network communications in order to form an appropriate innovation territorial cluster targeted to the production of knowledge-intensive goods and services capable of competing both at the Russian and global markets (see table 1).

Table 1. Economic Development Indicators of Tomsk Region

\begin{tabular}{lcccc}
\hline Indicator & 2010 & 2011 & 2012 & 2013 \\
\hline Quantity of economically active population, thousand persons & 540.2 & 512.6 & 494.5 & 516.0 \\
\hline Gross regional product, mln. RUB. in the current prices & 245808.3 & 284676.7 & 333885.7 & 374171.6 \\
\hline Industrial production index & 97.9 & 105.3 & 107.0 & 103.9 \\
\hline Investment in fixed capital, mln. RUB. . & 19401 & 77598 & 100897 & 107930 \\
\hline Innovational activity of organizations, \% & 15.3 & 18.4 & 15.7 & 11.4 \\
\hline
\end{tabular}

The program of developing the biochemical territorial cluster envisaged the direct impact of the cluster's activity on these indicators. For example, the number of people employed in the economy, will be increased by 20 thousand persons, the gross regional product will grow by 1500 million rubles. At the same time the negative dynamics of the industrial production index will be overcome and its sustainable growth will start while the innovation activity of the organizations will cease to drop down and will be able to exceed the 2011 level (Innovation in Russia 2015).

In 2012, a program of developing innovation territorial cluster "Pharmaceutics, Medical Equipment and Information Technologies of Tomsk Region" was approved for the period of 2012 to 2016. The principal target of the innovation territorial cluster was to provide high growth rates of the production volumes of science-intensive high-tech products within the region by using the key competitive advantage of the region, i.e., high concentration of intellectual human resources in the high education sector and in the R\&D sector by forming a result-oriented chain of expanding new knowledge, technology and innovations to the following fields:

1. Diagnostics;

2. Medical instruments and equipment;

3. Multi-component bio-composite medical materials;

4. Pharmaceutics.

The choice of the fields was determined by two basic factors:

1. Scientific relevancy because it is specifically these fields and their combination that produce effective modern treatment;

2. Broad experience in developing medical instruments and materials of the potential participants of the cluster (Department of Investments of Tomsk Oblast, 2015).

The cluster activity was targeted at the production of new types of medical products, such as medicinal preparations, high-tech raw materials for the pharmaceutical industry, diagnostic tools, instruments for surgical and diagnostic purposes, semiconductor-based instruments for implantation.

\section{Formation of Innovation Territorial Cluster "Pharmaceutics, Medical Equipment and Information Technologies" in the Tomsk Region}

\subsection{Organizational structure of the biomedical cluster}

The organizational structure of biomedical cluster of the Tomsk Region was formed based on the experience of producing cluster formations in the countries that lead in the cluster policy, of other Russian regions and with the account of regional specifics. The governing body of the cluster is its Coordination Council whose function involves the determining of target indices of the cluster development, assessment of the intermediate results, taking decisions as to the conformance of pharmaceutical organizations to the requirements to a cluster member. The Coordination Council may also take decisions 
on the supportive measures for the cluster members, implementation of innovation and research projects.

The Coordination Council of the cluster consists of the customer representative, representative of the scientific group and business-group representative. The customer representative is an employee of the Cluster Development Center. The scientific group representative is the Provost for Research of one of the higher educational or academic institutions of Tomsk. The business representative is one of the directors of the enterprises that form part of the biomedical cluster. He provides information about the project feasibility in one field or another.

The Department of Strategy comprising three sections is subordinated to the Coordination Council. Scientific Forecast Department determines upcoming scientific development trends in four fields: diagnostics; medical instruments and equipment; biomaterials; and pharmaceutics. Commercialization-and-Marketing Department is engaged in the search of financing sources, in market promotion of goods, it performs monitoring of the support by grants and funds via business agents and venture capital funds. Information-and-Legal Department ensures information and analytical support of the cluster communication with innovational infrastructures of the city, region, Russia, other countries of the world, and renders legal support.

The scientific research group of the cluster is composed of representatives of Tomsk State University, Tomsk Polytechnic University, Tomsk University of Control Systems and Radioelectronics, Siberian State Medical University, Institute of Physics of Strength and Materials Science of the Siberian Branch of the Russian Academy of Sciences. Besides solving the problems of fundamental science the group provides a continuous inflow of highly qualified personnel to small-scale enterprises, cluster participants that form production sites for implementing scientific research and development. The companies provide students and young scientists with the opportunity to undergo a training course at the research departments that develop innovation medicines (Strelyaeva, 2013).

The central body of the cluster is the Cluster Development Center that interacts with government authorities and other clusters.

For the two years of the Cluster's activity the interaction system of main Cluster stakeholders acquired stability and today the following properties of structure of the biomedical cluster of Tomsk Region can be regarded as positive:

1. Participation of universities and academic institutes with scientific traditions and highly qualified personnel as the Cluster stakeholders thus considerably reducing the expenses for training high-quality human resources.

2. Strong interrelation among science, business and regional authorities during the Cluster functioning resulting in certain benefits for all the members.

3. Availability of a large number of producing enterprises thereby increasing the possibility to select partners during the projects implementation and consequently improve the cluster performance quality and flexibility.

4. Direct involvement of the representatives of higher educational and scientific institutions in the Cluster organizational structures functioning.

\subsection{Cluster Participants and Partners}

By the end of 2014, there were 264 companies functioning in the structure of innovation territorial cluster "Pharmaceutics and Medical Equipment", 43 of the companies were the residents of Special Technology Development Economic Zone "Tomsk".

Presently, besides Cluster Policy Center, the Innovation Territorial Cluster of Pharmaceutics, Medical Equipment and Informational Technologies of Tomsk Region comprises:

1. Producers of pharmaceutical preparations and medical equipment and apparatus;

2. Higher educational institutions;

3. R\&D organizations.

The "anchor" enterprises of the cluster are major industrial pharmaceutical, medical and IT companies active both at Russian and international markets.

Most important pharmacy and medical equipment producers are OJSC "Farmstandart - Tomskhimfarm" the major producer of officinal medicines in Western Siberia that belongs to the company group "Farmstandart"; scientific production association "Virion" whose production is oriented to the manufacture of various vaccines and immunoglobulins; LLC "Novohim" established specifically for the implementation of an innovation project for constructing the production facility of glyoxal, the first in Russia; CJSC "Aldomed", small-scale innovation enterprise formed at Tomsk State University for the production of desinfectants based on glyoxal; LLC "Akvelit" that cooperates with Institute of Physics of Strength and Materials Science of the Siberian Branch of the Russian Academy of Sciences in the production of safety products for protecting drinking water from microbiological contaminants; LLC "Mednord-Tehnika", specialized in the production and sales of hardware and software complexes for clinical and diagnostic investigations of the rheological 
properties of blood; LLC «FRENSIS-medikal», a joint Russian («EleSy") and German ("Soering GmbH”) company for the high-tech production of a complete cycle of electric surgical diathermy machines of global-class standard as well as the equipment for oncology, neurology, psychiatry and many other uses.

Tomsk higher educational institutions and scientific research institutes whose scientific research and development activities are intended for small- and medium-scale enterprises of the cluster, play a very important part in the cluster's innovation system. These include Siberian State Medical University whose R\&D activities involve the development of bandaging materials, medicinal preparations, medical instrument engineering; National Research Tomsk State University specializing on the research of biocompatible shape memory composites; National Research Tomsk Polytechnic University whose R\&D fields are biotechnology and medical instrument engineering. The basic stakeholders of the cluster are scientific research institutes of the Russian Academy of Sciences and Russian Academy of Medical Sciences located in Tomsk, i.e., the institutes of pharmacology, medical genetics, oncology, biology and biophysics, microsurgery, cardiology as well as the Institute of Physics of Strength and Materials Science of the Siberian Branch of the Russian Academy of Sciences with their scientific research in the sphere of production of materials for medical use and implants.

Thus, the scientific and educational institutions are the brain trust of Tomsk territorial innovation cluster while the innovation enterprises producing two product ranges, (1) pharmaceuticals and (2) medical equipment and diagnostic apparatus are its production core, its main structural element ensuring the growth of output and employment.

\subsection{Cluster initiatives and projects}

Competitiveness and prospective market position, both at Russian and at foreign markets, of the majority of the enterprises - cluster members are attributable to the production use by the majority of these enterprises of the latest technological developments provided by Tomsk higher educational and research institutions.

The cluster members were therefore selected from among the enterprises functioning in the region that use innovation technologies of medicine and pharmaceutics and that are interested in the state financial support and are interested in the promotion of their development products to the global market of medical articles. In 2012 LLC "Akvelit" in particular, had finished development products in the sphere of medical materials and maintained a pilot production facility for nanofiber-based bandaging materials for septic and burning wounds with a capacity of 100 thousand dressings a month. According to the estimates made by Director of the Institute of Physics of Strength and Materials Science of the Siberian Branch of the Russian Academy of Sciences - if the project has been successfully performed by 2017 - Tomsk will cover $7 \%$ of the Russian market of bandaging materials; over 10 million dressings a year will be totally produced and the sales volume will amount to more than 1 milliard rubles.

In the cluster's activity, much importance is attached to the production of glyoxal. LLC "Novohim", a cluster member, is the only enterprise producing glyoxal in Russia based on a unique and unsurpassed synthesis process. LLC "Glyoxal-T" concentrates its efforts on the formation of a pilot production facility of glyoxal using a new generation of catalysts. Apart from that, production technologies for glyoxal-containing materials are being developed. For instance, CJSC "Aldomed" produces glyoxal-based desinfectants while LLC "Aldofarm" is the first enterprise in Russia which commercialized the production of imidasole whose price is lower than that of a Chinese equivalent but whose quality corresponds to European quality. At the same time all the small-scale enterprises, cluster members, use the cluster advantages to launch their developed articles to the market.

The cluster member universities are also active in producing innovation developments in medicine. Siberian State Medical University has developed vegetable-based medicinal preparations, medicinal preparations of synthetic origin, biologically active supplements, cryosurgical instruments, surgical instruments made from shape memory metals, gastrointestinal tract electrostimulators, orthopedic devices, and modern highly efficient treatment, diagnostic and preventive procedures. Tomsk Polytechnical University undertakes developments in various fields of biotechnology and medical instrument engineering. The Scientific Research Institute of Medical Materials and Shape Memory Implants of Siberian Physical-Technical Institute of the Tomsk State University investigates physical bases of producing biocompatible shape memory alloys and other technological processes in the material science field. So far the Institute obtained 351 patents for various types of implants used in dentology, traumatology, surgery, ophthalmology, oncology as well as unique technologies for surgical treatment.

By the end of the two years of their residence in the biomedical cluster all the members achieved certain results. Small-scale enterprises have a possibility to launch mass production of innovative medicinal preparations developed by Tomsk scientists for use in the living standard improvement and extension of the life duration of the population. LLC "Sintegal" produces "Galodif" preparation for treating patients suffering from epilepsy and alcohol addiction and develops other neurological and antiinfective preparations LLC "FRENSIS-medikal" produces electrosurgical aids as well as 
electric equipment for oncology, neurology and psychiatry. LLC "MedLine"produces contact electric impulse lithitriptor "Urolith", an innovative apparatus used to destroy urolith.

\section{Conclusion}

Thus, in the period between 2010 and 2014 Tomsk Region witnessed activities on formation and arrangement of functioning of territorial innovative cluster "Pharmaceutics, Medical Equipment and Information Technologies". A number of positive results were achieved during this period (table 2).

Table 2. Basic Indicators of the Cluster's Economic Progress

\begin{tabular}{|c|c|c|c|}
\hline Indicators & 2012 & 2013 & 2014 \\
\hline Quantity of personnel of the enterprises and organizations participating in the Cluster, persons. & 2200 & 2860 & 3258 \\
\hline Volume of cluster infrastructure financing, million rubles & 31351.5 & 46.8 & 197.5 \\
\hline $\begin{array}{l}\text { Consolidated sales revenues of the Cluster members from sales of non- primary products at the } \\
\text { local and foreign markets, milliard rubles. }\end{array}$ & 5.5 & 5.65 & 5.8 \\
\hline Share of Cluster sales in the Russian market volume, $\%$ & 3.4 & 3.5 & 3.55 \\
\hline Quantity of small- and medium-scale enterprises functioning in the Cluster & 142 & 302 & 378 \\
\hline
\end{tabular}

On $27^{\text {th }}$ February 2015, at Krasnoyarsk Economic Forum, the cluster submitted its activities report and the results of pilot investigation of the management system in innovative territorial clusters of the Russian Federation using methods of European system of cluster assessment ECEI (European Cluster Excellence Initiative); the assessment was arranged by the Association of Innovative Regions of Russia. Totally 19 clusters and management companies participated in the survey. As a result of the assessment, Cluster "Pharmaceutics, Medical Equipment and Information Technologies" gained the maximum amount of points, 825 points, and was ranked first thereby proving its efficiency and its development potential.

Presently the Center of Cluster Development of Tomsk Region has specified the activities plan of "Pharmaceutics and Medical Equipment" Cluster for the year 2015. In future it is planned to arrange for the cluster companies participation in exhibitions and forums of Russian and international levels. Among new preparations planned for production in 2015 in Tomsk Pharmaceutical cluster are the preparation for early detection and treatment of cancer, stem cell-based preparations, new biologically active supplements based on polyprenols. The list contains more than 70 items altogether.

\section{References}

Andersson, T. (2004). The Cluster Policies. Whitebook. Malmö: IKED.

Bergman, E. M. (1999). Industrial and Regional Clusters: Concepts an Comparative Applications. Morganton, WV: Regional Research Institute, West Virginia University.

Clark, B. R. (1998). Creating Entrepreneurial Universities: Organizational Pathways of Transformation. Issues in Higher Education. Oxford: Pergamon Press for International Association of Universities.

Department of Investments of Tomsk Oblast. The investment Department of the Tomsk region. [Online] Available: http://invest.tomsk. gov.rul (March 22, 2015).

Enright, M. (2000). Survey on the Characterization of Regional Clusters: Initial Results. Working Paper. Institute of Economic Policy and Business Strategy: Competitiveness Program University of Hong Kong. Barcelona: The Competitiveness Institute.

Freeman, C. (1995). The national system of innovation in historical perspective. Cambridge journal of economics, 19 (1), 5-24.

Inglehart, R. (1995). Changing values, economic development and political change. International Social Science Journal, 145, 379-403.

Innovation in Russia. The program of development of innovative territorial cluster "Pharmaceuticals and medical devices of the Tomsk region". [Online] Available: http://innovation.gov.ru/sites/default/files/documents/2014/5533/1001.pdf/ (March 22, 2015).

Kuznetsov, Y., Filimonova, N., \& Fedosova, R. (2014). Strategic development of small businesses in Russian regions. Asian Social Science, 10 (13), 231-238.

Raagmaa, G. (2002). Regional identity in regional development and planning. European Planning Studies, 10 (1), 55-76.

Simmie, J. (1999). Innovative clusters: global or local linkages. National Institute Economic Review,170 (1), 87-98.

Strelyaeva, A. E. (2013). Biomedical cluster in the Tomsk region. Features of the organizational structure. Siberian Medical Journal, 28(4),126-131.

Sztompka, P. (2004). The trauma of social change: A case of postcommunist societies. In: Cultural Trauma and Collective Identity (pp. 155-195). University of California Press.

Tiryakian, E.A. (2007). Sociological theory, constructal theory, and globalization. In: Constructal Theory of Social Dynamics (pp. 147- 
160). Durham: Springer Science and Business Media.

Tkachenko, V. G., \& Bogachev, V. I. (2014). Clusters in the system of agricultural production: the nature and importance in the implementation of the innovation policy of the state. [Online] Available: http://dspace.nbuv.gov.ua/bitstream/handle/123456789/ 45737/36Tkachenko.pdf?sequence=1 (March 22, 2015).

Tomskstat. Territorial body of the state statistics in the Tomsk region. [Online] Available: http://tmsk.gks.ru/wps/wcm/connect/ rosstat_ts/tmsk/rul (March 22, 2015). 